\title{
Dysgerminoma in Pseudohermaphroditism: A Case Report
}

\author{
Rashmey Pun ${ }^{1}$, Sujata Pudasaini ${ }^{2}$, Rita Mahaseth ${ }^{1}$, Kriti Shrestha ${ }^{1}$ \\ ${ }^{1}$ Clinical Oncology Unit, Department of Medicine, Nepal Medical College Teaching Hospital, Kathmandu, Nepal. \\ ${ }^{2}$ Department of Pathology, Nepal Medical College Teaching Hospital, Kathmandu, Nepal.
}

\section{ABSTRACT}

\begin{abstract}
Female pseudohermaphroditism occurs when normal ovaries are present but the body is partially masculinized as individuals with congenital adrenal hyperplasia, also known as adrenogenital syndrome. This is an inherited disorder that accounts for about one-half of all cases of human intersexuality. We report a case of a 24-year-old male presenting with abdominal pain and increasing abdominal distension for one month. Computed tomography scan revealed large multiloculated heterogeneously enhancing solid -cystic lesion in the abdominopelvic cavitymalignant gonadal mass, gross ascites, and visualization of the poorly formed elongated uterus-like structure in the recto-uterine pouch and phallus-like structure with non-visualization of bilateral testes. Histopathology report suggested germ cell tumor and immunohistochemistry confirmed the diagnosis of dysgerminoma. Since dysgerminoma is sensitive to platinum-based chemotherapy patient was subjected to chemotherapy and the patient showed a good response. The patient underwent exploratory laparotomy with right salpingo-oophorectomy with omentectomy and appendectomy.
\end{abstract}

Keywords: Dysgerminoma; Gonadal dysgenesis; Karyotyping; Pseudohermaphroditism

\author{
Correspondence: \\ Dr. Rashmey Pun \\ Clinical Oncology Unit, Department of Medicine \\ Nepal Medical College Teaching Hospital, Kathmandu, \\ Nepal \\ ORCID ID: 0000-0002-1743-2147 \\ Email: dr.rpun@gmail.com
}

Submitted: $20^{\text {th }}$ November 2020

Accepted: $18^{\text {th }}$ December 2020

Source of Support: None

Conflict of Interest: None

Citation: Pun R, Pudasaini S, Mahaseth R, Shrestha K. Dysgerminoma in Pseudohermaphroditism: A Case Report. NMJ 2020;3(2):384-7. DOI 10.3126/nmj. v3i2.34909

\section{INTRODUCTION}

Disorders of sex development (DSD) are congenital conditions characterized by atypical chromosomal, gonadal, or anatomical sex development. ${ }^{1}$ In 2006, a consensus statement was issued that recommended the use of the DSD classification to replace various terms that are no longer utilized, such as pseudohermaphrodite, intersex, and sex reversal, among others. ${ }^{2}$ Complete gonadal dysgenesis is characterized by a female phenotype, nonambiguous genitalia, the presence of Müllerian derivatives, gonadal dysgenesis, and a normal karyotype. ${ }^{3}$ One type of gonadal dysgenesis is female pseudohermaphroditism which is characterized by male or ambiguous genitalia coupled with a female karyotype (46 XX). ${ }^{4}$ External genitalia is masculinized congenitally when a female fetus is exposed to the excess androgenic environment. Congenital adrenal hyperplasia (CAH) mostly 21-hydroxylase deficiency, is the most common cause. ${ }^{5}$ Ovarian dysgerminoma is the most common malignant neoplasm. It can be associated with gonadal dysgenesis (pure and mixed form). ${ }^{6}$
Here, we present a case of dysgerminoma in pseudohermaphroditism. Written informed consent was obtained from the patient for publication.

\section{CASE REPORT}

A 24-year-old young man was referred to the Oncology Department of Nepal Medical College Teaching Hospital, Kathmandu with a chief complaint of abdominal pain and increasing abdominal distension recently. On physical examination, the patient was a petit-framed young man with a moderately low-pitched voice. He presented with gross ascites and a solid mass over the pelvic region which could not be appreciated well due to ascites. On examination of secondary sexual characters, we noticed gynecomastia in him (fig. 1A) and the genital examination looked intermediate between a typical clitoris and penis (fig. 1B and 1C). The scrotum was empty, no testes were palpable, and a small phallus. There was a urethral opening, just below the phallus. 
Since childhood, he has been regarded as a male and his life pattern was masculine. As a baby and even after puberty, since he was staying in a monastery, nobody took notice of neither his genital abnormality nor his increasing size of the breast.

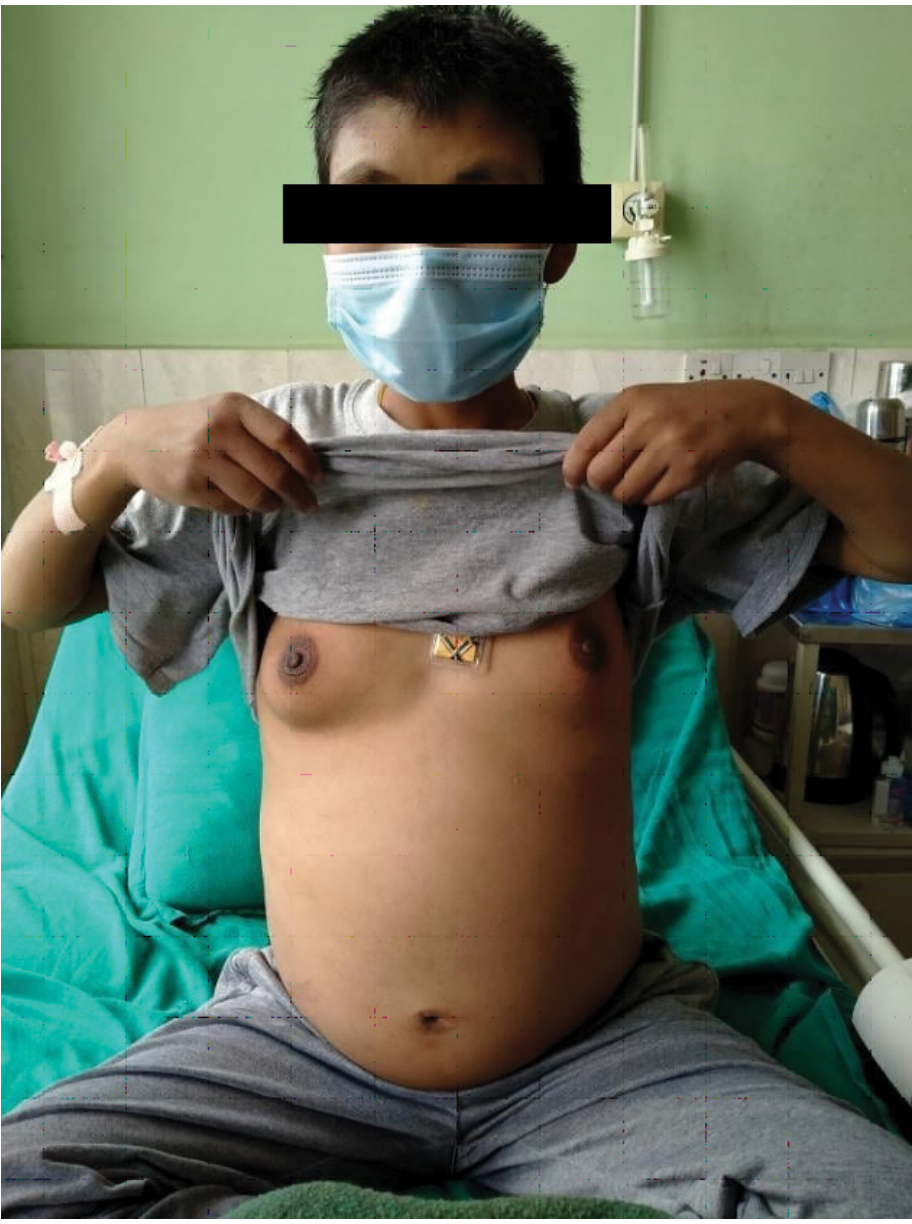

Figure 1A: Breast Examination showing Gynecomastia. ( Permission for publication was obtained)

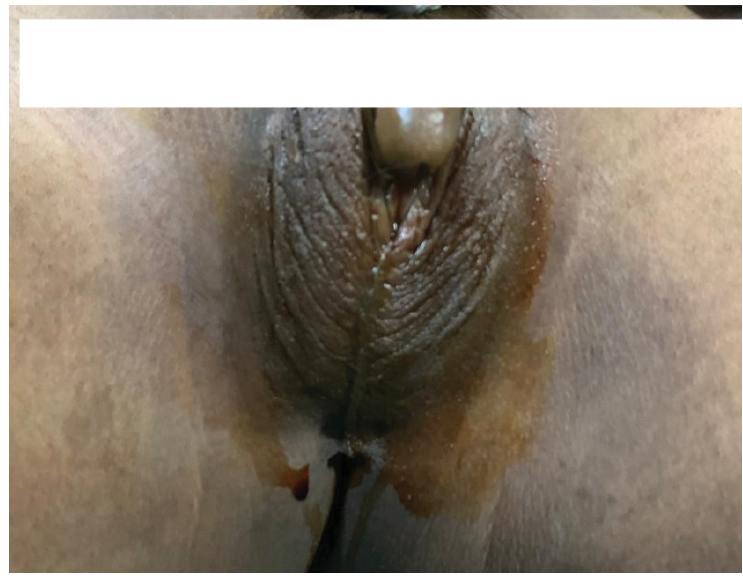

Figure 1B: Phallus, which looks intermediate between a typical clitoris and penis, below which, there is urethral opening. Empty labio-scrotal fold with rugae.

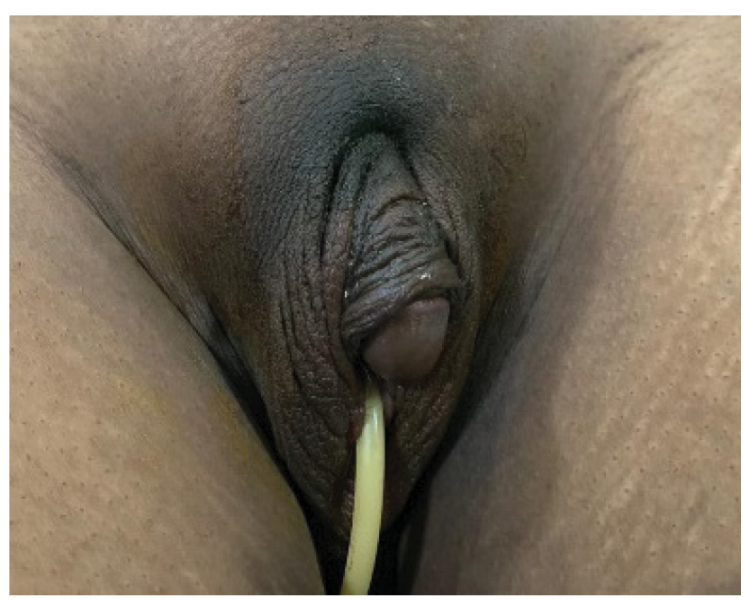

Figure 1C: Foley's Catheterization in the urethral opening, below phallus
Ultrasound of the abdomen was done which showed gross ascites. CT abdomen showed large multiloculated heterogeneously enhancing solid -cystic lesion in the abdominopelvic cavitymalignant gonadal mass, gross ascites, and visualization of the poorly formed elongated uterus-like structure in the rectouterine pouch and phallus-like structure with non-visualization of bilateral testes. On laboratory assessment complete blood counts, renal and liver functions were normal. Serum beta HCG: $323.28 \mathrm{IU} / \mathrm{ml}$, Alpha-fetoprotein (AFP): $2.36 \mathrm{ng} / \mathrm{ml}$, CA125: $788 \mathrm{U} / \mathrm{ml}$, and tremendously elevated LDH $-8545 \mathrm{U} / \mathrm{L}$. FSH $1.18 \mathrm{U} / \mathrm{L}, \mathrm{LH} 5.85 \mathrm{U} / \mathrm{L}$, and testosterone levels were low $(24.30 \mathrm{ng} / \mathrm{dl})$. Peritoneal fluid showed positive for malignancy probably adenocarcinoma. Therapeutic aspiration was done due to gross ascites. A trucut biopsy was done from the mass. On histopathology, the tumor cells are seen arranged in diffuse pattern exhibiting moderate pleomorphism, increased nuclear to cytoplasmic ratio, and some macronuclei. Mitosis was increased, 3-4/HPF. The differential diagnosis of surface epithelial tumor and malignant germ cell tumor was given (fig. 2A). Based on the histopathology report, we gave the patient chemotherapy with Cisplatin/Etoposide, and post the first cycle of chemotherapy his gross ascites subsided drastically and even the tumor mass regressed significantly. Immunohistochemistry of the biopsy was done which showed malignant germ cell tumor favoring dysgerminoma. To find out the presence of any chromosomal anomaly karyotyping was performed and the result showed there was 46, XX karyotype (fig.2B). Based on the clinical and laboratory findings, the diagnosis of pseudohermaphroditism and ovarian dysgerminoma was confirmed. 


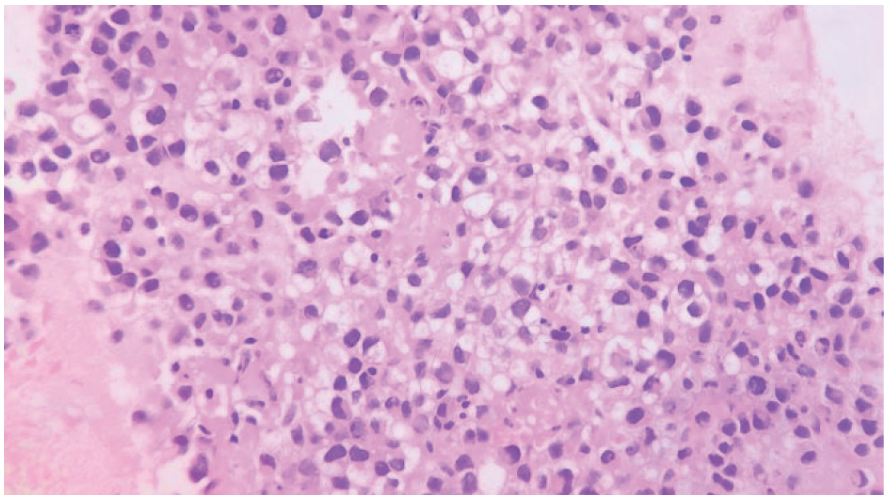

Figure 2A: Histopathology showing tumor cells in diffuse pattern exhibiting moderate pleomorphism, increased nuclear to cytoplasmic ratio and some macronucleoli,.

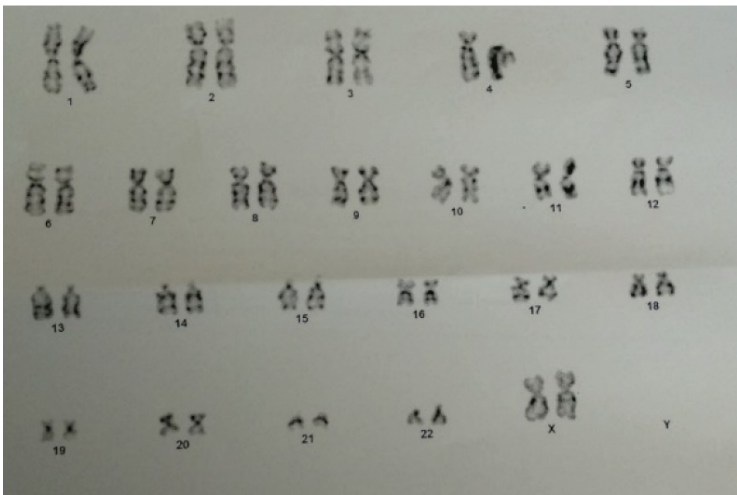

Figure 2B: Karyotping showing 46 XX Karyotype

Following the immunohistochemistry report, he received a second cycle with the BEP regime (Bleomycin, etoposide, and cisplatin). Three weeks after the first cycle of chemotherapy the LDH decreased to $840 \mathrm{U} / \mathrm{L}$ to and post-second cycle LDH has futher come down to $178 \mathrm{U} / \mathrm{L}$ and $\beta \mathrm{HCG}-2.39 \mathrm{IU} / \mathrm{ml}$.

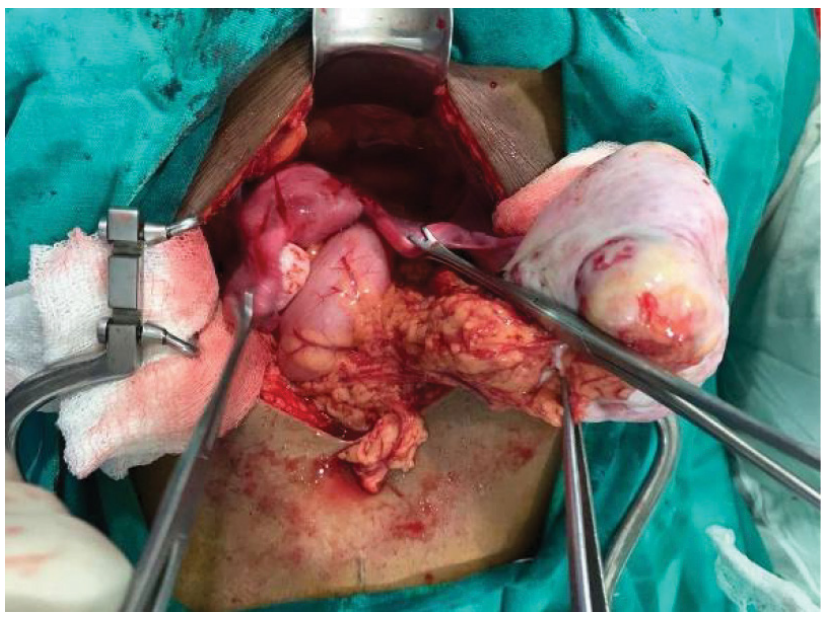

Figure 3A: Right Ovarian mass measuring $10 \times 8 \mathrm{~cm}$ with mild peritoneal adhesion

The patient underwent exploratory laparotomy right salpingoopherectomy with omentectomy and the per-operative finding showed mild peritoneal adhesion and right ovary with $10 \times 8 \mathrm{~cm}$ mass (fig. 3A). Cross-section of the mass showed necrosis and hemorrhages (fig. 3B) which was sent for histopathology and reported as negative for residual tumor. There was regression associated necrosis and fibro-infl ammatory changes.

Since the patient is genetically female due to 46XX karyotype, but socially and psychologically male, as an important aspect of postoperative treatment counseling was done Since dysgerminoma is highly sensitive to platinum - based chemotherapy, two cycles of chemotherapy (BEP regimen) were given $p$ ostoper atively. The patient is on follow-up and is doing well.

\section{DISCUSSION}

In a hermaphrodite, a tumor can arise either from ovarian tissue or testicular tissue, often the gonads are destroyed so that site of origin cannot be determined. ${ }^{7}$ A $50 \%$ of the ovotestes are found in an abdominal position, while $25 \%$ are in the inguinal region.

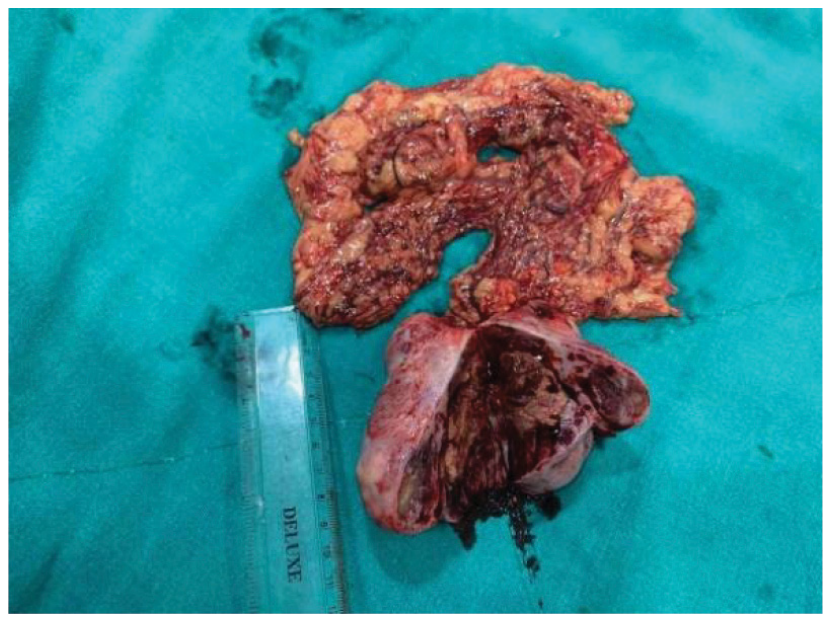

Figure 3B: Cross-section of Right Ovarian mass showing necrosis and hemorrhage with adjacent omentum

The other $25 \%$ are labioscrotal in position. An $85 \%$ of ovaries are found in the abdomen and $50 \%$ of the testes are labioscrotal. ${ }^{8}$ The type of internal genitalia found depends on the adjacent gonads. ${ }^{7}$ The gonads are at high risk for gonadal tumors, which are typically gonadoblastomas and/or dysgerminomas. ${ }^{9,10}$

Dysgerminomas are generally rare, accounting for less than $5 \%$ of ovarian tumors, but exhibit a high malignant potential. ${ }^{11}$ However, this type of tumor is found in one out of every three individuals with DSD. ${ }^{12}$ Dysgerminoma typically presents with abdominal pain (70-80\%) and a lower abdominal mass. ${ }^{13}$

Ovarian neoplasms have been associated with mild elevation of different enzymes considered as non-specific tumor markers. Lactic dehydrogenase (LDH) is a glycolytic enzyme that may be elevated in the serum of patients with gonadal and extragonadal germinomas. Assays of neoplastic tissue have shown high LDH activity $^{14,15}$ and serum levels of LDH are elevated in cancer patients $^{16-19}$ although this is not invariable. In 1964 Zondag was the first to recognize a different serum LDH isoenzyme pattern in patients with gonadal germinomas. ${ }^{20}$ 
Dysgerminomas are highly sensitive to chemotherapy, thus the use of chemotherapy has been associated with a remarkable increase in patient survival, particularly following the introduction of platinum-based regimes. ${ }^{21}$ Patients with disease presenting in stages IB, II, and III who wish to maintain fertility, unilateral oophorectomy followed by combination chemotherapy may be curative and spare ovarian function. Otherwise, complete surgery, followed by abdominopelvic radiation therapy, is recommended. This treatment produces less morbidity than chemotherapy and will cure approximately two-thirds of patients. Chemotherapy should be used for salvage of subsequent relapse. ${ }^{22}$

The survival rates of patients with XY gonadal dysgenesis and dysgerminoma are similar to survival rates of $\mathrm{XX}$ individuals with malignant ovarian germ cell tumors; in both types of patients, survival rates are largely dependent on tumor stage 14 . In particular survival rates are lower among patients with more advanced tumors (stages $2-4 ; 53.9 \%$ ) than among patients with stage I tumors $(96.9 \%)^{21}$

This case coupled with similar other reports in the literature indicates serum LDH may serve as a useful tumor marker for patients with gonadal and extragonadal germinomas (dysgerminomas, seminomas). Determination of total serum LDH levels and isoenzyme electrophoresis may be of value in the work-up of young patients with suspected ovarian or testicular masses. Patients whose preoperative serum LDH levels are high can be monitored for effectiveness of therapy when a residual tumor is being irradiated and for detection of a recurrent tumor during follow-up examinations.

\section{REFERENCES}

1. King TFJ, Conway GS. Swyer syndrome. Curr Opin Endocrinol Diabetes Obes. 2014; 21: 504-10. Crossref

2. Hughes IA, Houk C, Ahmed SF, Lee PA. Consensus statement on management of intersex disorders. J Pediatr Urol. 2006; 2: 148-62. Crossref

3. Lipay MVN, Bianco B, Verreschi ITN. Gonadal dysgenesis and tumors: genetic and clinical features (in Portuguese) Arq Bras Endocrinol Metabol. 2005; 49: 60-70. Crossref

4. Hongling Du, Hugh S. Taylor, Principles of Developmental Genetics (second edition) 2015 pages 487-504 $\underline{\text { Crossref }}$

5. Kamijo H, Narita O. Female pseudohermaphroditism. Nihon Rinsho Jap J Clin Med.1997; 55 : 2925-9. Website

6. Iqbal MB, Mushtaq I, Kambale T, Dey I. Swyer syndrome (46XY pure gonadal dysgenesis) presenting with dysgerminoma. Arch Med Health Sci. 2019;7: 248-50. Crossref

7. Ceci M, Callega E, Said E, Gut N. A case of true hermaphroditism presenting as a testicular tumor. Case Rep Urol. 2015; 2015: 598138. Crossref

8. Barseghyan H, Vilain E. The genetics of ovotesticular disorders of sex development. Genetic Steroid Dis. 2014: 261-63. Crossref

9. Langman, Jan; Thomas Sadler (2006). Langman's medical embryology. Hagerstown, MD: Lippincott Williams \& Wilkins. ISBN $0-7817-9485-4$

10. Scully R.E. Tumors of the ovary and maldeveloped gonads.In: Atlas of tumor pathology. Armed Forces Institute of Pathology. Editors: Scully, Robert E., Young, Robert H., Clement, Philip B. Washington D.C1978. p300-310

11. Burrows S. Serum enzymes in diagnosis of ovarian malignancy. Amer J Obs Gynecol. 1980; 137: 140-1. Crossref
12. Matsumoto F, Shimada K, Ida S. Tumors of bilateral streak gonads in patients with disorders of sex development containing $\mathrm{Y}$ chromosome material. Clin Pediatr Endocrinol. 2014; 23: 93-7 Crossref

13. Cecchetto G. Gonadal germ cell tumors in children and adolescents. J Indian Assoc Pediatr Surg. 2014;19: 189-94. Crossref

14. Goldman RD, Kaplan NO, Hall TC. Lactic dehydrogenase in human neoplastic tissues. Cancer Res 1964; 24:384-99

15. Meister A. Lactic dehydrogenase activity of certain tumors and normal tissues. J Nail Cancer Inst 1950; 101263-71

16. Hill BR, Levi C. Evaluation of a serum component in neoplastic disease. Cancer Res 1954; 14: 513-5

17. Zondag HA, Klein F. Clinical applications of lactate dehydrogenase isoenzymes: alterations in malignancy. Ann NY Acad Sci 1968; 15 1: 578-86. Crossref

18. Bierman HR, Hill BR, Reinhardt L, Emory F. Correlation of serum lactic dehydrogenase activity with the clinical status of patients with cancer, lymphomas and leukemias. Cancer Res 1957; 17:66077

19. White LP. Serum Enzymes. 11. Glycolytic enzymes in patients with cancer and other diseases. J Natl Cancer Inst 1958; 21: 671-84

20. Zondag HA. Enzyme activity in dysgerminoma and seminoma. A study of lactic dehydrogenase isoenzymes in malignant diseases (The 1963 Fiske Essay). Rhode Island Med J 1964; 47: 273-281

21. Lin KY, Bryant S, Miller DS, Kehoe SM, Richardson DL, Lea JS. Malignant ovarian germ cell tumor - role of surgical staging and gonadal dysgenesis. Gynecol Oncol. 2014; 134: 84-9 $\underline{\text { Crossref }}$

22. Thomas GM, Dembo AJ, Hacker NF, DePetrillo AD. Current therapy for dysgerminoma of the ovary. Obstet Gynecol. 1987 70: 268-75. Website 